\title{
Investigation of water adsorption on metal oxide surfaces under conditions representative of $\mathrm{PuO}_{2}$ storage containers.
}

\author{
Patrick Murphy ${ }^{1}$, Colin Boxall ${ }^{1}$ and Robin Taylor ${ }^{2}$ \\ ${ }^{1}$ Engineering Department, Lancaster University, Lancaster, LA1 4YR, UK \\ ${ }^{2}$ Central Laboratory, B170, National Nuclear Laboratories, Sellafield, Seascale, Cumbria, CA20 \\ $1 \mathrm{PG}, \mathrm{UK}$
}

\begin{abstract}
We have developed a QCM (Quartz Crystal Microbalance) based method for direct gravimetric determination of water adsorption on $\mathrm{PuO}_{2}$ surrogate surfaces, especially $\mathrm{CeO}_{2}$, under conditions representative of those in a typical $\mathrm{PuO}_{2}$ storage can. In this application, the method of transduction of the QCM relies upon the linear relationship between the resonant frequency of piezoelectrically active quartz crystals and the mass adsorbed on the crystal surface. The spurious effect of high temperatures on the resonant frequency of coated QCM crystals has been compensated for by modeling the temperature dependence of the frequency response of the surrogate coated-QCM crystal in the absence of water. Preliminary results indicate that water is readily adsorbed from the vapor phase into porous metal oxide structures by capillary condensation, an observation that may have important ramifications for water uptake within the packed powder beds that may obtain in $\mathrm{PuO}_{2}$ storage cans.
\end{abstract}

\section{INTRODUCTION}

Standardised packaging and storage of plutonium oxide powders involves sealing the materials in welded, stainless steel containers. Pressurization of these containers arises from decomposition of adsorbed water contained in and on the surface of hygroscopic $\mathrm{PuO}_{2}$ [1]. In an attempt to remove water from the surfaces of these oxides, and thus minimize pressurization, $\mathrm{PuO}_{2}$ samples are calcined at temperatures as high as $700^{\circ} \mathrm{C}$ but water often readsorbs onto the plutonia powders during packaging [2].

The potential of $\mathrm{PuO}_{2}$ to generate a water vapor-derived pressure in a storage can headspace is directly related to its capacity for $\mathrm{H}_{2} \mathrm{O}$ adsorption. This adsorption must be fully understood in order to reliably underpin the $\mathrm{PuO}_{2}$ interim storage safety case. Water adsorption on $\mathrm{PuO}_{2}$ has previously been investigated by measuring headspace pressure, as a function of temperature within a closed system containing a fixed quantity of $\mathrm{PuO}_{2}$ in the presence of varying amounts deliberately added water [1]. This involves making a number of assumptions relating to the PVT behaviour of the headspace of the closed system, usually based on the behaviour of an ideal gas, in order to estimate the mass of water adsorbed at the $\mathrm{PuO}_{2}$ surface. Assuming ideality at high temperatures and pressures is problematic and, at best, only gives an indirect measurement of water adsorption on $\mathrm{PuO}_{2}$.

The Quartz Crystal Microbalance (QCM) measures mass per unit area by measuring the change in frequency of a quartz crystal resonator. In our system we have coated QCM crystals with a $\mathrm{PuO}_{2}$ surrogate $\left(\mathrm{CeO}_{2}\right)$ so as to measure directly the mass of water adsorbing at the surrogate surface, thus avoiding many of the issues associated with indirect measurements inferred from PVT behavior. However, as well as responding to adsorbed mass, quartz crystal piezoelectrodes also respond to changes in temperature, exhibiting changes in their resonant 
frequency. For mass changes in a system with a dynamically changing temperature regime, this thermal effect can be compensated for by modelling the temperature dependence of the frequency response of a QCM crystal in the absence of water [3]. By extension, this approach can also be used for modelling the temperature response of $\mathrm{PuO}_{2}$ surrogate-coated crystals in the absence of water adsorption, so allowing for the gravimetric measurement of water adsorption at the surrogate surface as a function of temperature. Thus, this paper presents preliminary results relating to QCM-measured water adsorption on $\mathrm{CeO}_{2}$ coated crystals in a closed system representative of a $\mathrm{PuO}_{2}$ storage container, where the spurious affect of temperature change on the crystal's resonant frequency has been compensated for by the above modeling technique.

\section{EXPERIMENTAL DETAILS}

The QCM crystals used in this study were 5MHz, AT-cut wafers with polished gold electrodes on both sides (Testbourne Ltd). The crystal mass sensitivity factor was 0.0566 $\mathrm{Hz} / \mathrm{ng} / \mathrm{cm}^{2}$. Crystal dimensions were: $2.54 \mathrm{~cm}$ overall crystal diameter and $1.27 \mathrm{~cm}$ electrode diameter. The procedure for depositing thin films of $\mathrm{CeO}_{2}$ (as a $\mathrm{PuO}_{2}$ surrogate) onto these QCM crystals in the current work was adapted from the Lundberg [4] method. 1 mmol of $\mathrm{CeCl}_{3} .7 \mathrm{H}_{2} \mathrm{O}$ and $0.5 \mathrm{~g}$ of p123 Pluronic (a non ionic surfactant) was dissolved in $10 \mathrm{~g}$ of methanol. $100 \mu \mathrm{lof}$ the resulting solution was spin coated onto one face of the QCM crystal at 2900RPM for 10 seconds. The coated crystal was then calcinated in air at $400{ }^{\circ} \mathrm{C}$ for one hour, resulting in formation of an off-white layer which rigidly adhered to the QCM crystal. The diameter of the layer was roughly $2 \mathrm{~cm}$ (outermost edges of the quartz crystal remained uncoated).

A $100 \mathrm{ml}$ volume pressure vessel, constructed of 316L stainless steel with a maximum operating temperature of $275^{\circ} \mathrm{C}$ was used to simulate conditions of a $\mathrm{PuO}_{2}$ storage container. The vessel was heated and its temperature controlled via an IKA ${ }^{\circledR}$ RET Basic safety control hotplate and IKA ${ }^{\circledR}$ ETS-DS Electronic Contact Thermometer which uses a PID control mechanism. The vessel was heated from its base by the hotplate. Addition of water into the vessel was achieved by removal of the vessel head for 1 second while water was injected. The crystals were mounted within the pressure vessel in a Pressure Equalized Crystal Holder $(\mathrm{PECH})$, designed and constructed in-house, where both sides of the crystal were exposed to the pressurized environment of the vessel. The PECH was constructed of PTFE and was installed in the vessel using a wire gland purchased from Conax Technologies ${ }^{\circledR}$. The PECH covered the edge of the QCM crystal and left an inner crystal diameter of $1.8 \mathrm{~cm}$ exposed to the environment within the vessel. This corresponds to an exposed area of $2.545 \mathrm{~cm}^{2}$.

Measurement of water adsorption on $\mathrm{CeO}_{2}$ coated crystals was achieved as follows: The $\mathrm{CeO}_{2}$ coated QCM crystals were installed in the PECH holder and then placed in the vessel. The vessel temperature was controlled at $25^{\circ} \mathrm{C}$ and the vessel was purged with $\mathrm{N}_{2}$ (moisture content of $2 \mathrm{ppm}$ ). The temperature within the vessel was increased from $25^{\circ} \mathrm{C}$ to $50{ }^{\circ} \mathrm{C}, 100{ }^{\circ} \mathrm{C}$ and finally $150{ }^{\circ} \mathrm{C}$ in a stepwise fashion. The temperature was held at the desired value until a steady value of frequency fluctuation (less than $+/-2 \mathrm{~Hz}$ at $50{ }^{\circ} \mathrm{C}$ and $100{ }^{\circ} \mathrm{C}$ and $+/-8 \mathrm{~Hz}$ at $150{ }^{\circ} \mathrm{C}$ ) was observed for 40 minutes. The vessel was then cooled back down to $25^{\circ} \mathrm{C}$. The $\mathrm{CeO}_{2}$ coated crystals were thermocycled in this fashion until twice they exhibited the same frequency response to temperature change. This was recorded as the crystal's temperature response in dry conditions. After the last of these dry thermocycles, the vessel's temperature was held at $25^{\circ} \mathrm{C}$ for 24 hours, whilst recording the frequency behaviour of the $\mathrm{CeO}_{2}$ coated crystal. $100 \mu \mathrm{l}$ $(100 \mathrm{mg})$ of water was then introduced into the vessel and its temperature again held at $25^{\circ} \mathrm{C}$ for 
24 hours whilst recording the crystal's frequency behaviour. These two frequency traces were compared as a means of measuring water adsorption on $\mathrm{CeO}_{2}$ at $25^{\circ} \mathrm{C}$. The vessel was then heated using the same stepwise temperature regime described earlier. The crystal's temperature response in dry conditions was used as a baseline against which water adsorption on $\mathrm{CeO}_{2}$ at high temperatures was measured.

\section{DISCUSSION}

This work involves the deposition of a layer of $\mathrm{CeO}_{2}$ onto the surface of a quartz crystal nanogravimetric transducer and the use of the resultant ceria-crystal composite to measure the mass of water adsorbed at the metal oxide surfaces as a function of temperature. However, in the first instance, the effect of the presence of $\mathrm{CeO}_{2}$ on the QCM response needs to be determined. Deposition of a ceria layer onto QCM crystals typically resulted in a resonant frequency drop of $1240 \mathrm{~Hz}$. This corresponds to a mass change of $21.9 \mu \mathrm{g} / \mathrm{cm}^{2}$. Thus $55.7 \mu \mathrm{g} \mathrm{of} \mathrm{CeO}_{2}$ was exposed to the pressurized environment within the cell by the PECH holder when installed in the pressure vessel. AFM imaging of the quartz-ceria interface on the edge of the QCM crystal (not shown) suggests the layer is approximately $100 \mathrm{~nm}$ thick. From the mass deposited and the known density of $\mathrm{CeO}_{2}\left(7.65 \mathrm{~g} / \mathrm{cm}^{3}\right)$ [5], the volume of the ceria layer has been calculated to be $7.287 \mathrm{x}$ $10^{-6} \mathrm{~cm}^{3}$. The thickness of a perfect (non porous) cylinder with volume $7.287 \mathrm{~cm}^{3} \times 10^{-6} \mathrm{~cm}^{3}$ and radius $0.9 \mathrm{~cm}$ is equal to $28.6 \mathrm{~nm}$. Comparing this value with the observed layer thickness suggests that the $\mathrm{CeO}_{2}$ layer is highly porous, with over $70 \%$ of its volume comprised of voids.

\section{Temperature response of $\mathrm{CeO}_{2}$-coated QCM crystal in dry conditions.}

Due to the sensitivity of the resonance behavior of QCM crystals to temperature change, the temperature response of $\mathrm{CeO}_{2}$ crystals needed to be quantified in the absence of adsorbing water. Thus, the response of a QCM crystal coated with $\mathrm{CeO}_{2}$ to repeated thermocycling in a sealed, dry vessel was recorded and is shown in Figure 1. During the first cycle, when cooling from $150{ }^{\circ} \mathrm{C}$ to $25^{\circ} \mathrm{C}$, the $\mathrm{CeO}_{2}$ coated crystal's frequency drops $110 \mathrm{~Hz}$ below its starting frequency at $25^{\circ} \mathrm{C}$. For the subsequent $2^{\text {nd }}, 3^{\text {rd }}$ and $4^{\text {th }}$ cycles the crystal's frequency returns to its starting frequency upon cooling. Advantageously, the temperature response of the $\mathrm{CeO}_{2}$ coated crystal is identical for cycles 3 and 4 . Thus, this temperature response was used as a baseline against which to measure water adsorption on this particular $\mathrm{CeO}_{2}$ coated QCM crystal.

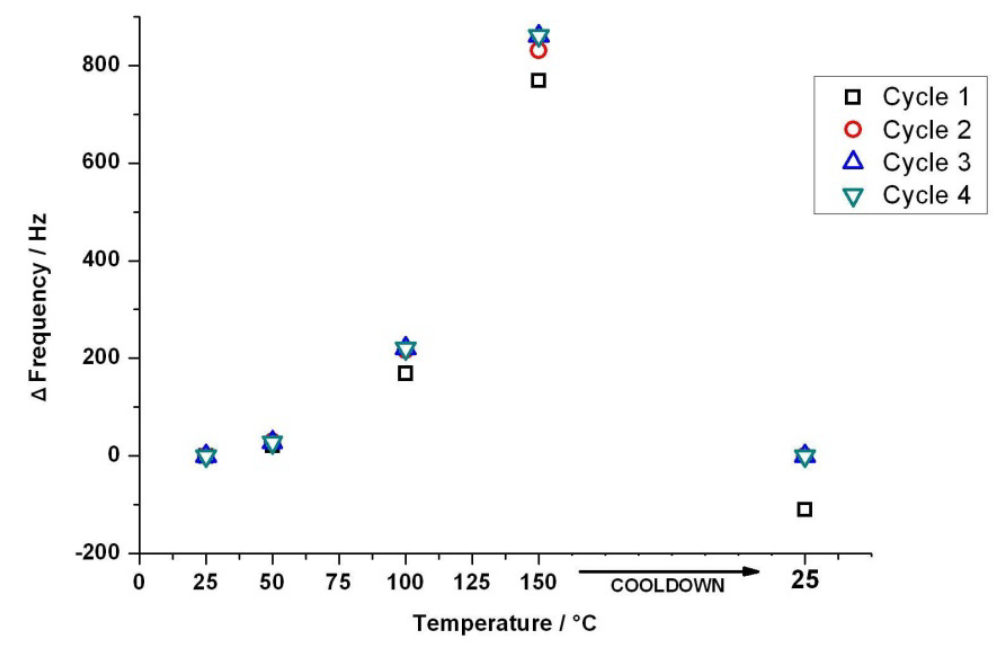

Figure 1: Repeated Thermocycling of a $\mathrm{CeO}_{2}$ coated QCM crystal in dry conditions 


\section{Water adsorption on $\mathrm{CeO}_{2}$ at $2^{\circ} \mathrm{C}$.}

Figures 2(a) and (b) show the results of water adsorption experiments on a $\mathrm{CeO}_{2}$ coated crystal at $25{ }^{\circ} \mathrm{C}$ over a 26 hour period. As described in the experimental section, this experiment was conducted by mounting the crystal within a sealed pressure vessel, purging with dry $\mathrm{N}_{2}$ and introduction of $100 \mathrm{mg}$ of water to the vessel post-purging. Assuming the entire $100 \mathrm{mg}$ of water introduced into vessel has completely evaporated and taking the saturation pressure of water at $25^{\circ} \mathrm{C}$ to be $3165 \mathrm{~Pa}$ [6], the relative humidity within the vessel was $100 \%$
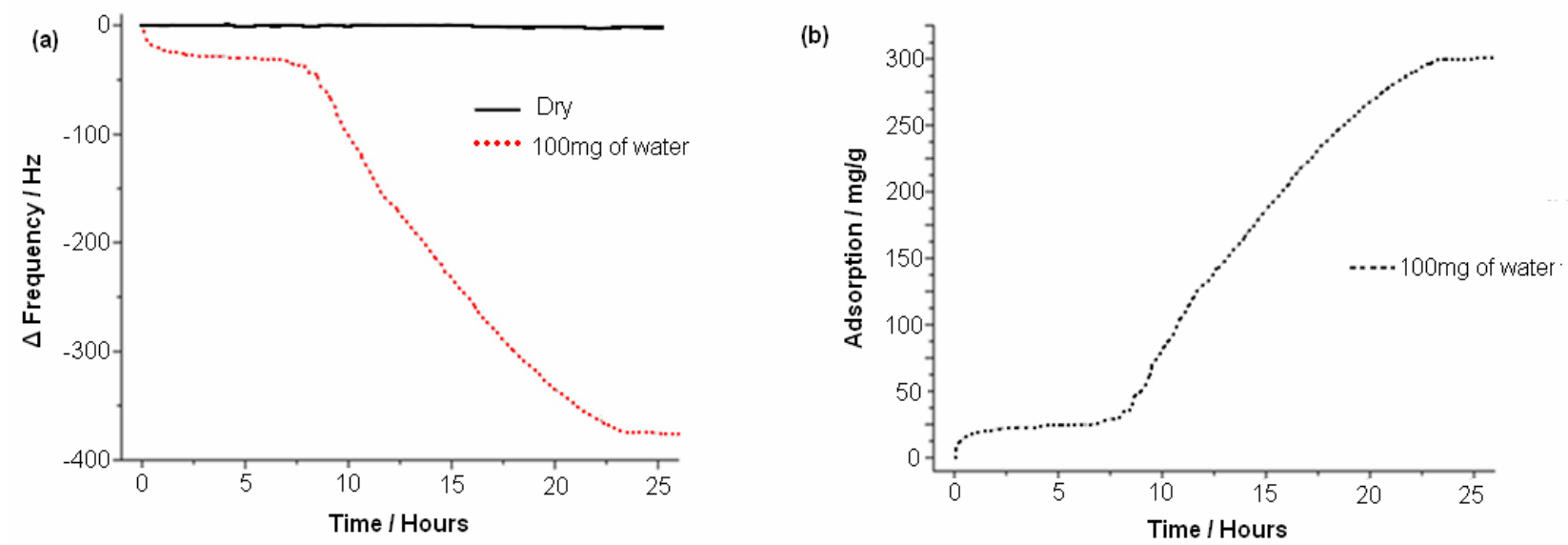

Figure 2: (a) Raw Frequency response of the $\mathrm{CeO}_{2}$ coated crystal before and after addition of $100 \mathrm{mg}$ grams water. (b) Mass adsorbed on the $\mathrm{CeO}_{2}$ layer, expressed as milligram of adsorbate (water) per gram of adsorbent $\left(\mathrm{CeO}_{2}\right)$.

From Figure 2(a) three distinct of stages of adsorption can be observed: Addition of water into the vessel results in a frequency change of $-20 \mathrm{~Hz}$ after 1 hour. A more gradual frequency change of $10 \mathrm{~Hz}$ is observed over the next six hours. The rate of frequency decrease then increases dramatically resulting in a frequency change of $-380 \mathrm{~Hz}$ after 23 hours. Figure 2(b) shows the same data, recast as mass of adsorbate adsorbed / unit mass of adsorbent with the recorded mass increasing as a result of water uptake on the coated crystal. The shape of Figure 3(b) strongly resembles a Type IV BET adsorption isotherm for adsorption in a mesoporous solid [7]. A plausible explanation for what is happening in Figure 2(b) is that, consistent with the Type IV isotherm, adsorption initially occurs over the interior surface of the $\mathrm{CeO}_{2}$ pore structure prior to pore filling. This analysis is supported the adsorbed mass/time data at times longer than 7 hours. Considering that the voidage within the ceria layer before exposure to $100 \% \mathrm{RH}$ was earlier calculated to be $>70 \%$, the mass of water adsorbed after 7 hours in Figure 2(b) corresponds to a remaining voidage within the layer of $65 \%$. This indicates that after 7 hours the pores within the $\mathrm{CeO}_{2}$ layer are not full of adsorbed water and that adsorption had been occurring on the interior surface of $\mathrm{CeO}_{2}$ pore structure. Conversely after 23 hours the remaining voidage within the layer is only $2 \%$. Taking into account that the layer thickness of $100 \mathrm{~nm}$ is an approximate measurement and the shape of the adsorption curve from 7 to 23 hours shown in Figure 2(b) strongly resembles capillary condensation associated with a Type IV isotherm, it appears likely that the pore structure within the layer has been completely filled with adsorbed water after 23 hours. 
The mass of water adsorbed at $25^{\circ} \mathrm{C}$ and $100 \% \mathrm{RH}$ of $300 \mathrm{mg} / \mathrm{g}$ is relatively high compared to literature values recorded for $\mathrm{PuO}_{2}$ powder samples. Moseley [8] recorded a value of $50 \mathrm{mg} / \mathrm{g}$ for water adsorption $\mathrm{PuO}_{2}$ powder at $25^{\circ} \mathrm{C}$ and $100 \% \mathrm{RH}$. A likely explanation for the relatively large amount of adsorption seen in Figure 2(b) is the highly porous nature of the $\mathrm{CeO}_{2}$ sample. This porosity means the layer is likely to have a very high surface area. Thus, BET surface area-analysis needs to be conducted on the $\mathrm{CeO}_{2}$ samples used in the current work and compared to typical surface areas of $\mathrm{PuO}_{2}$ powders stored held interim storage containers. This work is currently underway.

\section{Water adsorption on $\mathrm{CeO}_{2}$ up to $150{ }^{\circ} \mathrm{C}$.}

In order to form a preliminary view of the temperature dependence of the water uptake seen in Figure 2, a $\mathrm{CeO}_{2}$ coated crystal was heated to $150{ }^{\circ} \mathrm{C}$ in the same stepwise regime described earlier. Its frequency response was recorded in the presence and absence of $100 \mathrm{mg}$ of added water within the vessel as a means of measuring water adsorption/desorption at high temperatures. This comparison is seen in Figure 3(a). Figure 3(b) shows the corresponding mass data for water adsorbed on the $\mathrm{CeO}_{2}$ sample, calculated by the difference in delta frequency between the dry and wet cycles at each temperature stall (the dry experiments of Figure 1 having already demonstrated that after four dry cycles, the frequency response of the surrogate coated crystal as a function of temperature is highly reproducible).
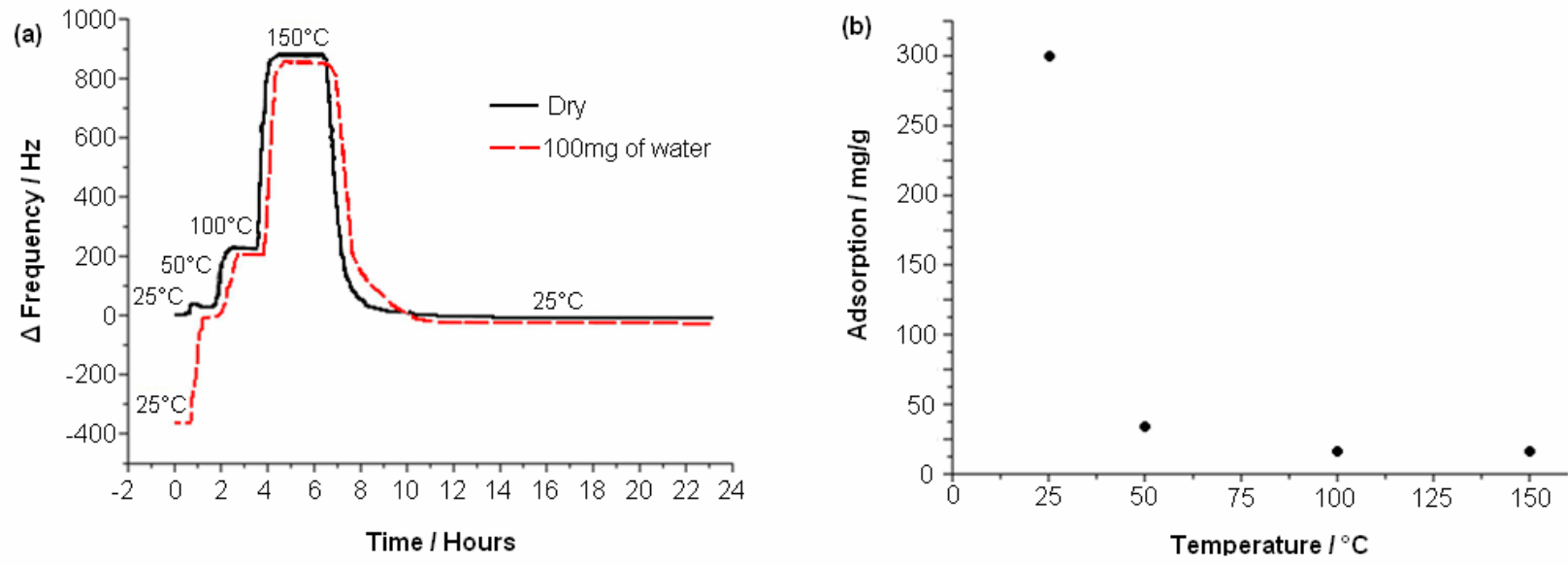

Figure 3: (a) Frequency response of the $\mathrm{CeO}_{2}$ coated crystal after addition of $100 \mathrm{mg}$ of $\mathrm{H}_{2} \mathrm{O}$ into the vessel, compared to the crystal's dry temperature response. (b) Adsorption versus temperature graph up to $150^{\circ} \mathrm{C}$.

Figure 3(b) shows that a high percentage of $89 \%$ of the water adsorbed at $25^{\circ} \mathrm{C}$ was desorbed by heating the vessel to $50{ }^{\circ} \mathrm{C}$. Further heating to $100^{\circ} \mathrm{C}$ and $150{ }^{\circ} \mathrm{C}$ resulted in much smaller mass losses, with $95 \%$ of the water being desorbed from the $\mathrm{CeO}_{2}$ coated crystal at $150{ }^{\circ} \mathrm{C}$. A control experiment where an uncoated gold QCM was crystal was exposed to the same temperature regime (not shown) and same \% RH showed no adsorption taking place on the gold surface between 50 and $150^{\circ} \mathrm{C}$, so mass changes at these temperatures are as a result of water adsorption on $\mathrm{CeO}_{2}$. The thermally induced desorption shown in Figure 3(b) is similar to that seen by Stakebake [9] for thermal desorption of water from $\mathrm{PuO}_{2}$ powders under vacuum using a 
conventional microbalance. For comparison, Stakebake observed that a large percentage of the adsorbed water ( $70 \%$ approx.) is desorbed by heating to $50{ }^{\circ} \mathrm{C}$. Through mass spectrometry and study of adsorption enthalpies both Stakebake and Hasckhe [10] have attributed this to desorption of physisorbed water molecules from $\mathrm{PuO}_{2}$ by gentle heating. Chemisorbed hydroxyl groups, formed by the dissociation of water remain on the $\mathrm{PuO}_{2}$ surface at temperatures as high as 900 ${ }^{\circ} \mathrm{C}$ [9]. It is likely the remaining adsorbed mass further recorded at $150{ }^{\circ} \mathrm{C}$ seen in Figure 2(b) is in the form chemisorbed hydroxyl groups. It is noticeable in Figure 3(a) that upon cooling the vessel from $150{ }^{\circ} \mathrm{C}$ back to $25^{\circ} \mathrm{C}$, very little readsorption of water onto the $\mathrm{CeO}_{2}$ layer occurs. In an isothermal system, one would expect to see an adsorption curve similar to the one shown in Figure 2(a) upon cooling the vessel back to $25^{\circ} \mathrm{C}$. This discrepancy is likely to have been caused by water condensing in "cold spots" within the vessel's valves during the heating cycle, as these valves are far away from the hotplate heating source. We are in the process of addressing this experimental artifact by the application of band heaters to these parts of the reactor.

\section{CONCLUSIONS}

A Quartz Crystal Microbalance-based technique has been developed for measuring water adsorption on $\mathrm{PuO}_{2}$ surrogate surfaces at temperatures as up to $150{ }^{\circ} \mathrm{C}$. Studies on mesoporous $\mathrm{CeO}_{2}$ layers as $\mathrm{PuO}_{2}$ powder analogues indicate that significant water adsorption / condensation can occur within the capillary network/pore structure of the ceria layer. Temperature dependent studies indicate that as much as much as $5 \%$ this water remains adsorbed at $150^{\circ} \mathrm{C}$. As proof-ofconcept has been achieved, the next step is to adopt an experimental rig which is more representative of a typical $\mathrm{PuO}_{2}$ storage container, i.e. an isothermal vessel with a higher temperature limit.

\section{REFERENCES}

1. M. T. Paffett et al, J. Nuc. Mat., 322 (2003) 45

2. US Department of Energy, US DOE/DP-0123T (1994)

3. D. Wang et al, Colloids and Surfaces, 268 (2005) 30

4. M. Lundberg et al, Microporous and Mesoporous Mat., 54 (2002) 97-103

5. P. Paitnaik, Handbook of Inorganic Chemicals, (2002) McGraw -Hill

6. R. S. Khurm-Chand, Steam Tables with Molliers Charts, (2008) Chand

7. D. Shaw, Introduction to Colloid and Surface Chemistry, (1992) Butterworth-Heinemann

8. J.D. Moseley, US DOE Report RFP-503 (1965)

9. J. L. Stakebake, J. Phys. Chem., 77 (1973) 581-586

10. J. M. Haschke et al, J. Alloy Compd., 252 (1996) 148-156 